\title{
Patient safety culture and job stress among nurses in Mazandaran, Iran
}

\author{
Saeed Asefzadeh ${ }^{1}$, Rohollah Kalhor ${ }^{2}$, Mohammad $\operatorname{Tir}^{3}$
}

${ }^{1}$ Ph.D. in Health Services Management, Professor, School of Health, Qazvin University of Medical Sciences, Qazvin, Iran

${ }^{2}$ Ph.D. in Health Services Management, Assistant Professor, Social Determinants of Health Research Center, Qazvin University of Medical Sciences, Qazvin, Iran

${ }^{3}$ M.Sc. Student in Health Services Management, Department of Health Services Management, School of Health, Qazvin University of Medical Sciences, Qazvin, Iran

\section{Type of article: Original}

\begin{abstract}
Background: Paying attention to patient safety is a basic right and a necessary issue in providing medical care, and failure to observe it leads to irreparable damage. One of the factors affecting an individuals' performance in an organization is stress, which also endangers their health.

Objective: To determine the relationship between patient safety culture and levels of job stress among the nurses working in the hospitals affiliated with Mazandaran University of Medical Sciences.

Methods: The present study was carried out using a cross-sectional method in the hospitals affiliated with Mazandaran University of Medical Sciences in 2016. A multistage stratified sampling method using a Morgan Table was employed to select 380 nurses as the study sample from among 3,180 nurses. They were selected by a multistage stratified sampling method. The study instruments were Stinemetz Standard Job Stress Questionnaire and Hospital Survey on Patient Safety Culture (HSOPSC). After the required data were collected, they were analyzed using descriptive and inferential statistical methods (Pearson correlation, independent-samples t-test, and ANOVA) through SPSS version 23.

Results: The results of the present study showed that $75 \%$ of the nurses experienced average and high levels of stress. Among different dimensions of safety culture, organizational learning and handoffs and transitions obtained the highest and the lowest scores, respectively (72.5 and 24.5). The mean score of safety culture dimensions was 51.52. The results of the Pearson correlation test showed that there was a direct significant relationship between different dimensions of safety culture among nurses and the level of stress ( $\mathrm{p} \leq 0.05)$.

Conclusion: According to the findings, patient safety should be considered as a strategic priority for the senior managers of the health system. In order to enhance patient safety, managers should pay special attention to evaluating safety culture in organizations that deliver health service, especially hospitals.

Keywords: Job stress, Nurse, Patient safety culture, Governmental hospitals, Iran
\end{abstract}

\section{Introduction}

In modern societies, health systems and hospitals are constructed to deliver high quality services to provide patients with health care and treatment. Care quality is composed of some elements, and patient safety is one of the most important of them (1). The issue of patient safety means to avoid causing any damage or injury to the patients while providing health care, which has become more observed by health policymakers over the last few decades (2). Adverse events and medical errors are among challenges that health systems in all countries are faced with, and they attempt to minimize them and reduce the damages caused by them (3). It is estimated that 5 to $10 \%$ of health-related

\section{Corresponding author:}

Mohammad Tir, Health Services Management Department, School of Health, Qazvin University of Medical Sciences, Shahid Bahonar Blv, Qazvin, Iran.

Tel: +98.9113912806, Fax:+98.2833345862,E-mail: m_tir53@yahoo.com

Received: March 19, 2017, Accepted: August 17, 2017, Published: December 2017

iThenticate screening: August 15, 2017, English editing: November 25, 2017, Quality control: Dcember 12, 2017

This article has been reviewed / commented by four experts

(C) 2017 The Authors. This is an open access article under the terms of the Creative Commons Attribution-NonCommercialNoDerivs License, which permits use and distribution in any medium, provided the original work is properly cited, the use is non-commercial and no modifications or adaptations are made. 
costs are resulted from unsafe clinical services which lead to patients' further suffering, and here, the failure of the system plays a greater role than that of the individual (4). One out of 10 patients that are admitted to hospital experience adverse events, half of which are preventable. One third of such events cause harm to the patients' wellbeing and may prolong the hospitalization period or even death (5). Safety culture is the result of individual and group values, attitudes, perceptions, competencies, and patterns of behavior which represents an organization's commitment, method, and skill with regard to safety management (6). The characteristics of an efficient safety culture include the senior manager's commitment with regard to learning from mistakes, documenting them and improving patient safety, encouraging group work, discovering potential risks, employing systems for reporting and analyzing adverse events, and applauding employees who help improve patient safety. In fact, the organization's long-term commitment to enhance quality and improve patient safety can be established by improving patient safety culture (7). Patients expect that the care system and the nurses provide them with high quality services. Despite the medical personnel's attempts and the availability of extensive facilities, patients' dissatisfaction is increasing, which has roots in the doctors and nurses' failure to communicate with the patients (8). Job stress is one of the main causes of decreased productivity in organizations and the reason for physical and psychological complications among employees. Since they are responsible for the patients' health and treatment, practitioners of medical professions are exposed to various stressful factors (9). According to the World Health Organization, over 50\% of personnel in industrialized countries are complaining about stressful workplaces (10). In England, it is estimated that after musculoskeletal disorders, job stress is the most important occupational health problem, and the cost of diseases and stress-related absenteeism is estimated to be 40 billion pounds per year (11). Nursing is a stressful job (12). Existence of job stress among nurses can influence their performance in all aspects including patient safety (13). Nursing involves vital activities and thus is associated with high levels of job stress (14). Stress has a significant relationship with the individual's performance and is an effective factor in the individuals' health, safety, and comfort (15). The American National Institutes of Health (NIH) stated that among 130 stressful jobs, nursing is placed 27th due to the problems caused by mental health (5). According to the results of different studies, every week $7.4 \%$ of nurses choose to be absent from work due to fatigue or stress-related disability, which is at $80 \%$ more than other jobs (16). In their study of nursing-related stress in Ethiopia in 2016, Dagget et al. indicated that the highest level of stress was related to the nurses faced with caring for dying patients, with a score of $62.94 \%$. The results of their study showed that job-related stress was different across different business units (17). Numerous studies of job stress among nurses showed that nurses have at least an average level of stress. Here, patient safety, the managers' belief about its special place, and observance of safety principles by nurses can be considered as main measures to be taken in order to reduce job stress among nurses. Since, along with providing health care, nurses are responsible for playing their role in keeping patient safety, observing safety principles while delivering daily care can lead to a decrease in adverse events and damages (18). Given the significance of job stress and observance of patient safety culture among nurses who account for most of the population employed in a health system, and due to a lack of national and international research into this issue, the present study was carried out in order to examine the relationship between patient safety culture and the level of job stress among nurses working in the hospitals affiliated with Mazandaran University of Medical Sciences in 2016.

\section{Material and Methods}

The present study was an analytical descriptive investigation that was carried out using a cross-sectional method in 20 hospitals affiliated with Mazandaran University of Medical Sciences in 2016. The statistical population included all nurses working in those 20 hospitals and with a work experience of more than 6 months. A multistage stratified sampling method using Morgan Table was employed to select 380 nurses as the study sample (considering $10 \%$ loss) from among 3,180 nurses. Finally, the questionnaires were randomly distributed among the nurses and were collected after they were completed (by maintaining the confidentiality of information), and 350 questionnaires (92\% of the distributed questionnaires) were completed and returned. Inclusion criteria was nurses who had at least one year experience in studied hospitals and a willingness to participate in the study, and exclusion criteria was nurses' reluctance to participate in the study. The ethical code of this study is IR.QUMS.REC.1395.33. The data were collected through 2 standard questionnaires. The first questionnaire was Hospital Survey on Patient Safety Culture (HSOPSC) that was designed in 2004 by the Agency for Healthcare Research and Quality (AHRQ) (19). The questionnaire compromises 42 items that cover 12 dimensions of patient safety culture. In addition, the questionnaire also includes two questions about the overall grade on patient safety and the number of events reported over the past 12 months in their ward/unit. Moghri et al. translated the questionnaire into Persian and used confirmatory factor analysis technique to standardize its construct validity and reliability. In their study, they used Cronbach's Alpha method, and the reliability of the questionnaire was reported to be 0.82 (20). The questionnaire was scored using a 5-point Likert scale. The second questionnaire was Stinemetz Standard Job Stress Questionnaire. 
It was translated into Persian by Attar in 1995 (21). The reliability of the questionnaire was reported in the Sarvghad study by Cronbach's Alpha 0.78 (22). It consists of 36 items on stressful situations of the workplace, which are scored using a 3-point Likert scale ranging from completely correct (2), to some extent correct (1) to incorrect (0). Scores of 29 and below indicate low job stress, scores between 30 and 42 indicate average job stress, and scores 43 72 indicate high levels of job stress. Finally, the collected data were analyzed using descriptive and inferential statistical methods (Pearson correlation, independent-samples t-test, and ANOVA) through IBMC SPSSC Statistics version 23 (IBMC Corp., Armonk, NY, USA).

\section{Results}

Totally, 350 nurses participated in the study that mean and standard deviation of the participants' age were $34.78 \pm 7.51$. Out of the participants, $302(86.3 \%)$ were women, 273 (78\%) were married, 333 (95.1\%) had a B.Sc. degree in nursing. and only one individual $(0.3 \%)$ had an associate's degree. The highest number of error reports in a year was more than 6 errors by 46 individuals (13.1\%) and the lowest number of errors in a year was 6 errors by 11 individuals $(3.1 \%)$. The results also showed that the minimum error report in a year was 1 case and the maximum was 80 cases with a mean of 6.65 and a standard deviation of 9.39 . According to the results of the present study, the minimum score of patient safety given by the nurses in the units was 2 out of 20 and the maximum was 20 with a mean and standard deviation of $16.52 \pm 2.42$ (Table 1). The results of the present study showed that mean and standard deviation of stress among the nurses were $37.82 \pm 13.31$. Out of the participants, 139 nurses (39.7\%) were suffering from moderate level stress, who had the highest share of stress score, 78 nurses $(22.3 \%)$ had a low level of stress, and 123 nurses (35.1\%) had a high level of stress. The results also showed that among different aspects of safety culture, organizational learning with a score of 72.5 and mean and standard deviation of $3.70 \pm 0.56$ received the highest score, and handoffs and transitions with a score of 24.5 and mean and standard deviation of $2.55 \pm 0.78$ received the minimum score. The mean score of the 12 aspects of patient safety in the present study was 51.52 (Table 2).

Table 1. Background information of studied nurses

\begin{tabular}{|l|l|l|l|}
\hline Variables & Quantity & Frequency & Percent \\
\hline Age & $20-30$ & 95 & 27.1 \\
\cline { 2 - 4 } & $31-40$ & 153 & 43.7 \\
\cline { 2 - 4 } & $41-50$ & 87 & 24.9 \\
\cline { 2 - 4 } & Higher than 51 & 15 & 4.3 \\
\hline \multirow{4}{*}{ Gender } & Male & 48 & 13.7 \\
\cline { 2 - 4 } & Female & 302 & 86.3 \\
\hline Marital status & Single & 77 & 22 \\
\cline { 2 - 4 } & Married & 273 & 78 \\
\hline
\end{tabular}

Table 2. Scores of twelve dimensions of patient safety culture among studied nurses

\begin{tabular}{|l|l|l|l|l|}
\hline Row & Safety culture dimensions & Mean & SD & $\begin{array}{l}\text { Mean percentage of } \\
\text { respondents }\end{array}$ \\
\hline 1 & Nonpunitive response to error & 3.23 & 0.87 & 46.8 \\
\hline 2 & Handoffs and transitions & 2.55 & 0.78 & 24.5 \\
\hline 3 & Staffing & 3.35 & 0.51 & 60.8 \\
\hline 4 & Teamwork across units & 3.35 & 0.51 & 46.6 \\
\hline 5 & Communication openness & 3.04 & 0.56 & 35.9 \\
\hline 6 & Frequency of events reported & 3.2 & 0.91 & 41.6 \\
\hline 7 & Feedback and communication about error & 3.43 & 0.77 & 49.6 \\
\hline 8 & Overall perceptions of patient safety & 3.05 & 0.5 & 62.9 \\
\hline 9 & Management support for patient safety & 3.3 & 0.51 & 51.9 \\
\hline 10 & Organizational learning-continuous improvement & 3.7 & 0.56 & 72.5 \\
\hline 11 & Supervisor/manager expectations and actions promoting safety & 3 & 0.56 & 55.6 \\
\hline 12 & Teamwork within units & 3.51 & 0.54 & 69.6 \\
\hline Average size of twelve patient safety culture dimensions & & & 51.52 \\
\hline
\end{tabular}

The results of Pearson correlation test showed that different aspects of patient safety among nurses had a reverse and significant relationship with the level of stress, nonpunitive response to error and handoffs and transitions, but a 
direct and significant relationship with other aspects at a level of $0.05(\mathrm{p} \leq 0.05)$ (Table 3$)$. The results of the present study regarding the relationship between job stress among the nurses and their background characteristics, showed that there was a significant relationship only among sex, work shift, and work hours per week $(p \leq 0.05)$. There was no significant relationship between the level of stress an age, marital status, employment type, education, and work experience in the hospital $(\mathrm{p}>0.05)$. The results of the Pearson correlation test also indicated that there was a significant difference between different dimensions of patient safety among the nurses and their age, and work experience in the hospital $(\mathrm{p} \leq 0.05)$.

Table 3. Relationship between dimensions of patient safety culture with the level of stress among studied nurses

\begin{tabular}{|l|l|l|l|l|}
\hline \multirow{2}{*}{ Safety culture dimensions } & \multicolumn{4}{|l|}{ Statistical indicators } \\
\cline { 2 - 6 } & $\mathrm{n}$ & $\gamma$ & $\mathrm{p}$-value & $\gamma^{2 * *}$ \\
\hline Nonpunitive response to error & 336 & -0.39 & $0.00^{*}$ & 0.152 \\
\hline Handoffs and transitions & 334 & -0.46 & $0.00^{*}$ & 0.211 \\
\hline Staffing & 337 & 0.25 & $0.00^{*}$ & 0.062 \\
\hline Teamwork across units & 338 & 0.19 & $0.00^{*}$ & 0.036 \\
\hline Communication openness & 339 & 0.18 & $0.001^{*}$ & 0.032 \\
\hline Frequency of events reported & 340 & 0.41 & $0.00^{*}$ & 0.168 \\
\hline Feedback and communication about error & 339 & 0.37 & $0.00^{*}$ & 0.136 \\
\hline Overall perceptions of patient safety & 333 & 0.16 & $0.002^{*}$ & 0.025 \\
\hline Management support for patient safety & 339 & 0.18 & $0.001^{*}$ & 0.032 \\
\hline Organizational learning-continuous improvement & 337 & 0.19 & $0.00^{*}$ & 0.036 \\
\hline Supervisor/manager expectations and actions promoting safety & 338 & 0.26 & $0.00^{*}$ & 0.067 \\
\hline Teamwork within units & 338 & 0.19 & $0.00^{*}$ & 0.036 \\
\hline
\end{tabular}

* Significant Relationship; **Coefficient of Determination

\section{Discussion}

The results of the present study showed that mean and standard deviation of stress among the nurses were respectively $37.82 \pm 13.31$. Out of the participants, $39.7 \%$ of the nurses were suffering from average stress, $22.3 \%$ had low stress, and $35.1 \%$ had high levels of stress. This level of stress can be due to reference of many patients to the hospitals on most days of the year because most cities of the province are tourist attractions. Moreover, inappropriate use of the manpower and ignorance of their skills and abilities in ICU and emergency ward can lead to an increase in stress among the nurses. The results of the study carried out by Dagget et al. in Ethiopia showed that the maximum and minimum scores of stress were respectively 116 and 26 with a mean and standard deviation of $58.46 \pm 12.62$. That study showed that job stress was seen in three levels of low, average, and high. The highest level of job stress was $62.94 \%$ which was observed among the nurses who were faced with patients' death and dying patients (17). In a study in South Africa, Khamisa concluded that mental fatigue and stress had the highest level of variance in mental health among nurses. These factors endanger productivity and efficiency, and also affect the quality of care, safety hazards in the workplace, job satisfaction, and health among nurses. These results are outstanding in developing countries and are significant in creating governmental interfering strategies and programs in order to improve the nurses' and patients' consequences (23). In their investigation into the scale of job stress among the nurses of one of the military hospitals in Tehran in 2012, Donyavi et al. concluded that 185 of the statistical population had low stress, 33\% average stress, 39\% high stress, and $9.8 \%$ very high stress (24). Ghasemi et al. carried out a study in Zanjan and reported the high level of stress among nurses at $57.4 \%$, the average level $40 \%$, and the low level $2.6 \%$ (25). Like the present study, Samadi et al. reported that average stress had the highest level (26). In the present study, among different aspects of safety culture, organizational learning with a score of $72.5 \%$ and handoffs and transitions with a score of $24.5 \%$ received the highest and the lowest scores, respectively. The mean score of the 12 aspects of patient safety in the present study was $51.52 \%$ which indicates an average level of patient safety culture in hospitals of Mazandaran province. In Turkey, Top showed that management support for patient safety with $80 \%$ had the highest score (27). Like the present study, in their study in China, Nie et al. reported that organizational learning and teamwork and communication openness received the highest scores among different aspects of patient safety (28). In agreement with the present study, the results of a study carried out in France showed that organizational learning had the highest effect on safety culture (29). The main reasons for the weakness in the handoffs and transitions in this study may be the lack of inter-departmental management in the studied hospitals and the lack of a systematic view of the interconnected units. One of the main reasons for the existence of an organizational learning approach and continuous improvement is the implementation of programs for improving 
the quality of hospital services, such as clinical governance, accreditation, and health system reform, which have had a great impact on improving the quality of hospital services in the country. The results of the study carried out by Saber showed that management support for patient safety, with a mean positive response of $72.20 \%$ received the highest score and nonpunitive response to error with 56.30\% had the lowest score (30). In their study, Mohebbifar and Alijanzadeh (2015) concluded that the aspects of frequency of events reported and handoffs and transitions respectively with 56 and 55 had the minimum means. According to the results of the present study, organizational learning and supervisor/manager expectations and actions both with a mean score of $69 \%$ received the highest means. The mean of patient safety culture in the studied hospitals was $63 \%$ (31). In their study, Azmal et al. used the HSOPSC questionnaire in Bushehr, and concluded that the highest positive response was related to organizational learning, and the lowest percentage was related to nonpunitive response to errors (32). The results of the present study with regard to the relationship between different aspects of safety culture among the nurses and the level of their job stress showed that there was a poor direct significant relationship among nonpunitive response to errors, staffing, teamwork across units, communication openness, overall perceptions of patient safety, management support for patient safety, organizational learning, and supervisor/manager expectations and actions promoting safety, and there was an average direct significant relationship between handoffs and transitions and feedback and communication and job stress $(\mathrm{p} \leq 0.05)$. Safi reported that there was neither a significant relationship between aspects of job stress and patient safety nor between total job stress and patient safety, and concluded that job stress had no effect on patient safety (8). In their study, Berland et al. (2008) examined the effect of job stress among nurses caused by high work demands and low work and organizational support on patient safety (33). Among the limitations of the present study, one can refer to dispersal of the hospitals and the participants' conservatism and low cooperation in filling out the questionnaires due to their busy schedule.

\section{Conclusions}

Regarding the observation, there is a significant relationship between stress level and patient safety culture between nurses in the studied hospitals. It is recommended that the level of patient safety and safety culture should be enhanced in hospitals so that stressful factors in the nursing workplace can be identified and a program can be proposed in order to reduce the level of job stress among the nurses who work in hospitals. Moreover, precise programs need to be designed with regard to the 12 aspects of patient safety, especially those with minimum scores such as frequency of events reported, communication openness, and handoffs and transitions.

\section{Acknowledgments:}

This study was part of a M.Sc. thesis at Qazvin University of Medical Sciences. We extend our gratitude to the participants, the hospital's nurses in Mazandaran for participating in this study and helping us to acquire the data we needed. The authors certify that no funding has been received for the conduct of this study.

\section{Conflict of Interest:}

There is no conflict of interest to be declared.

\section{Authors' contributions:}

All the authors had a role in designing the study. The first and second authors had the role in conducting the data analysis and interpretation of data. The third author contributed to the data acquisition and to writing the preliminary draft of the manuscript. All authors read and approved the final manuscript.

\section{References:}

1) Smits M, Christiaans-Dingelhoff I, Wagner C, Wal GV, Groenewegen PP. The psychometric properties of the 'Hospital Survey on Patient Safety Culture' in Dutch hospitals. BMC Health Serv Res. 2008; 8: 230. doi: 10.1186/1472-6963-8-230. PMID: 18990256, PMCID: PMC2588576.

2) Nash DB, Goldfarb NI. The quality solution: the stakeholder's guide to improving health care. 1st edition. Jones \& Bartlett Learning; 2005.

3) Bodur S, Filiz E. "Validity and reliability of Turkish version of" Hospital Survey on Patient Safety Culture" and perception of patient safety in public hospitals in Turkey." BMC Health Serv Res. 2010; 10: 28. doi: 10.1186/1472-6963-10-28. PMID: 20109186, PMCID: PMC2835702.

4) El-Jardali F, Jaafar M, Dimassi H, Jamal D, Hamdan R. The current state of patient safety culture in Lebanese hospitals: a study at baseline. Int J Qual Health Care. 2010; 22(5): 386-95. doi: 10.1093/intqhe/mzq047. PMID: 20699233. 
5) Mwachofi A, Walston SL, Al-Omar BA. Factors affecting nurses' perceptions of patient safety. Int J Health Care Qual Assur. 2011; 24(4): 274-83. doi: 10.1108/09526861111125589. PMID: 21938973.

6) Sammer CE, Lykens K, Singh KP, Mains DA, Lackan NA. What is patient safety culture? A review of the literature. J Nurs Scholarsh. 2010; 42(2): 156-65. doi: 10.1111/j.1547-5069.2009.01330.x. PMID: 20618600.

7) Allen S, Chiarella M, Homer CS. Lessons learned from measuring safety culture: An Australian case study. Midwifery. 2010; 26(5): 497-503. doi: 10.1016/j.midw.2010.07.002. PMID: 20692077.

8) SafiKeykale M. Relationship Between Nurses Job Stress and Patient Safety in Hamadan Teaching Hospitals, Tehran University of Medical Sciences Public Health. Thesis of Master of Science. 2015.

9) Osipow SH, Spokane AR. Occupational stress inventory-revised. Odessa, FL: Psychological. 2007; 25.

10) Torshizi L, Ahmadi F. Job Stressors from Clinical Nurses' Perspective. Iran Journal of Nursing. 2011; 24(70): 49-60.

11) Edwards D, Burnard P. systematic review of stress and stress management interventions for mental health nurses. J Adv Nurs. 2003; 42(2): 169-200. doi: 10.1046/j.1365-2648.2003.02600.x. PMID: 12670386.

12) Letvak S, Buck R. Factors influencing work productivity and intent to stay in nursing. Nurs Econ. 2008; 26(3): 159-65. PMID: 18616053.

13) Sorra JS, Dyer N. Multilevel psychometric properties of the AHRQ hospital survey on patient safety culture. BMC Health Serv Res. 2010; 10: 199. doi: 10.1186/1472-6963-10-199. PMID: 20615247, PMCID: PMC2912897.

14) Sveinsdóttir H, Biering P, Ramel A. Occupational stress, job satisfaction, and working environment among Icelandic nurses: a cross-sectional questionnaire survey. Int J Nurs Stud. 2006; 43(7): 875-89. doi: 10.1016/j.ijnurstu.2005.11.002. PMID: 16360157.

15) Hsu HY, Chen SH, Yu HY, Lou JH. Job stress, achievement motivation and occupational burnout among male nurses. J Adv Nurs. 2010; 66(7): 1592-601. doi: 10.1111/j.1365-2648.2010.05323.x. PMID: 20492017.

16) Motie MR, Samadi A, Eshaghi H, Ghobadi P. Prevalence of job sterssors in male prehospital emergency technicians. J Fundam Ment Health. 2010: 12(1): 420-9.

17) Dagget T, Molla A, Belachew T. Job related stress among nurses working in Jimma Zone public hospitals, South West Ethiopia: a cross sectional study. BMC Nurs. 2016; 15: 39. doi: 10.1186/s12912-016-0158-2. PMID: 27313502, PMCID: PMC4910212.

18) Hemmati maslakpak $M$, Habibzadeh $H$, Khalizadeh $H$. Managers and nurses function of safe patients' care from the nurses Perspective. Journal of Health Promotion Management. 2012; 1(2): 7-14.

19) Nieva VF, Sorra J. Safety culture assessment: a tool for improving patient safety in healthcare organizations. Qual Saf Health Care. 2003; 12 Suppl 2: ii17-23. doi: 10.1136/qhc.12.suppl_2.ii17. PMID: 14645891, PMCID: PMC1765782.

20) Moghri J, Ghanbarnezhad A, Moghri M, Rahimi Forooshani A, Akbari Sari A, Arab M. Validation of Farsi version of hospital survey on patient Safety culture questionnaire, using confirmatory factor analysis method. Journal of Hospital. 2012; 11(2): 19-30.

21) Attar H. investigating the relationship between job stress and job satisfaction with mental health industrial complex. Master's thesis, University of Medical Sciences. 1995.

22) Mostaghni S, Sarvghad S. Relationship of personality characteristics and psychological hardiness with job stress of nurses of public sector hospitals in Shiraz. Knowledge \& Research in Applied Psychology. 2013; 13(4): 124-32.

23) Khamisa N, Oldenburg B, Peltzer K, Ilic D. Work related stress, burnout, job satisfaction and general health of nurses. Int J Environ Res Public Health. 2015; 12(1): 652-66. doi: 10.3390/ijerph120100652. PMID: 25588157, PMCID: PMC4306884.

24) Donyavi V, Koohian K, Soleiman Meigooni S, Akbari M. Survey of occupational stress scale on nurses in a military hospital in Tehran-2012. Nurse and Physician Within War. 2012; 19: 9-13.

25) Mortaghy Ghasemi M, Ghahremani Z, Vahediane Azimi A, Ghorbani F. Nurse's job stress in a therapeutic educational center in Zanjan. Journal of Gorgan Bouyeh Faculty of Nursing and Midwifery. 2011; 8(1): 42 51.

26) Samadi S, Golmohammadi A, Seyedahmadian S, Rezapour T, Panahi H. The relationship between job stress and occupational empowerment of nurses in selected military hospitals of the country. Journal of Police Medicine. 2013; 2(1): 31-7. 
27) Top M, Tekingündüz S. Patient Safety Culture in a Turkish Public Hospital: A Study of Nurses' Perceptions About Patient Safety. Systemic Practice and Action Research. 2015; 28(2): 87-110. doi: 10.1007/s11213-014-9320-5

28) Nie Y, Mao X, Cui H, He S, Li J, Zhang M. Hospital survey on patient safety culture in China. BMC Health Serv Res. 2013; 13: 228. doi: 10.1186/1472-6963-13-228. PMID: 23800307, PMCID: PMC3701538.

29) Occelli P, Quenon JL, Kret M, Domecq S, Delaperche F, Claverie O, et al. Validation of the French version of the Hospital Survey on Patient Safety Culture questionnaire. Int J Qual Health Care. 2013; 25(4): 45968. doi: 10.1093/intqhe/mzt047. PMID: 23833029.

30) Saber M, Tehrani H, Hasani Kabootarkhani M, Ghorban Sabagh M, Bagheri M. Acquaintance of Kerman Hospitals' Staff about Patient Safety Culture. Journal of Health and Development. 2015; 4(2): 124-32.

31) Mohebbifar R, Alijanzadeh M, Safari Variani A, Khoshtarkib H, Ghanati E, Teymouri F, et al. Studying patient safety culture from the viewpoint of staffs in educational hospitals in Tehran City. Journal of health and safety at work. 2015; 5(1): 57-64.

32) Azmal M, Omranikho H, Goharinezhad S, Kalhor R, Fadaei Dehcheshmeh N, Farzianpour F. A Comparative Assessment of Patient Safety Culture between Iranian Selected Hospitals and Agency for Healthcare Research and Quality (AHRQ) Report. Health. 2014; 6(21): 3037-44. doi: 10.4236/health.2014.621342.

33) Berland A, Natvig GK, Gundersen D. Patient safety and job-related stress: a focus group study. Intensive Crit Care Nurs. 2008; 24(2): 90-7. doi: 10.1016/j.iccn.2007.11.001. PMID: 18096388. 